\title{
Monte Carlo Simulation for Cost Forecasting in the Green Building Project
}

\author{
Faridah Muhamad Halil, Hafiszah Ismail, \\ Mohamad Sufian Hasim, Halim Hashim
}

Centre of Studies for Quantity Surveying, Faculty of Architecture Planning and Surveying, Universiti Teknologi MARA,Shah Alam, Malaysia

faridahmh@uitm.edu.my, hafiszah@uitm.edu.my,moham315@uitm.edu.my

Tel. $+6017-2022145$

\begin{abstract}
Monte Carlo Simulation is a mathematical technique that generates random variables for modelling risk. This technique is suitable and benefits to the various client such as public and private sector to evaluate the costing prepared by the Quantity Surveyor. The methodology used is a qualitative approach consisting of a case study and document analysis. The result shows through Monte Carlo simulation, can predict the worst return from the accuracy of the estimation and given absolute confidence for project development.
\end{abstract}

Keywords: Monte Carlo, Risk Analysis, Cost Prediction, Qualitative Approach

eISSN 2398-4279 @2020 The Authors. Published for AMER ABRA cE-Bs by e-International Publishing House, Ltd., UK. This is an open access article under the CC BY-NC-ND license (http://creativecommons.org/licenses/bync-nd/4.0/). Peer-review under responsibility of AMER (Association of Malaysian Environment-Behaviour Researchers), ABRA (Association of Behavioural Researchers on Asians) and $c E-B s$ (Centre for EnvironmentBehaviour Studies), Faculty of Architecture, Planning \& Surveying, Universiti Teknologi MARA, Malaysia.

DOI: https://doi.org/10.21834/ajqol.v5i18.204 


\subsection{Introduction}

Cost overruns commonly occur in the construction project; one of the factors contributes to the cost overrunsthe Quantity Surveyor unable to estimate accurately during the precontract stage. (Ali Touran, 2006) elaborates on the many factors are responsible for thesecost overruns such as underestimation of cost to make the project more viable, the addition of scope during later stages of project planning and even during construction, changed condition and others. Based on the factors also contribute to the project delay in the construction industry due to not enough budget allocation for the proposed construction.Therefore, an accurate model is crucial for the Quantity Surveyor to use monte Carlo software to test the accuracy of the cost estimate prepared in the client's project. In Malaysia, the use of Software to predict the uncertainty of cost only based on the "5 to $10 \%$ rule". The percentage is used for the cost contingency from the total cost of the construction. Therefore, failure to predict the cost, the client will suffer to allocate further budget in the development. The needs of an appropriate probabilistic model to predict the accuracy of cost in the construction project. Therefore, the study aim is to analyse the concept of Monte Carlo practice in predicting the cost estimate in the Green Building Project.

\subsection{Literature Review}

The literature review highlighted the concept of Monte Carlo method practice in the construction industry. It's cover the definition of monte Carlo, method of estimating using monte Carlo, types of a forecasting method, benefits of monte Carlo and process of monte Carlo to predict the cost estimate.

\subsection{Definition of Monte Carlo}

The problems that exist in forecasting the future or even investigating the enormous of combinations of shapes, specification and use of buildings make it a task that cannot be entirely solved by a simple mathematical expression. (Ferry \& Brandon, 1979) describe the Monte Carlo technique is simply a way of sampling from distributions, in a random manner to provide a range of solutions which may be directed to finding the best solution. What is attempted by the method is to simulate a series of future events. Table 1.0 below shows the definition of Monte Carlo simulation by the various researchers.

Table 1.0 Definitions of Monte Carlo simulation

\begin{tabular}{|c|c|c|}
\hline Author(s) & Year & Definition of Monte Carlo simulation \\
\hline Hertz & 1964 & $\begin{array}{l}\text { "As a tool to estimate risk in capital markets, and employs the mode, } \\
\text { spread, and skewness of probability distributions to describe/model } \\
\text { uncertainty from various sources and produce a distribution of the } \\
\text { possible outcomes by randomly selecting input values from the } \\
\text { predetermined distributions." }\end{array}$ \\
\hline $\begin{array}{l}\text { Marquez et } \\
\text { al. }\end{array}$ & 2005 & $\begin{array}{l}\text { "Monte Carlo produces probability distributions of functions, including } \\
\text { distribution and mean square deviation." }\end{array}$ \\
\hline Faris and & 2007 & "Monte Carlo simulation is a technique that combines historical data \\
\hline
\end{tabular}




\begin{tabular}{|c|c|c|}
\hline Patterson & & $\begin{array}{l}\text { with inputs from S.M.E.s to assign a weight or probability of the } \\
\text { occurrence of a certain risk throughout a project." }\end{array}$ \\
\hline El-Sadek & 2010 & $\begin{array}{l}\text { "Monte Carlo simulation, like any other simulation model tries to } \\
\text { approximate real-world processes and interactions at a mechanical } \\
\text { level." }\end{array}$ \\
\hline $\begin{array}{l}\text { Jahangirian } \\
\text { et al. }\end{array}$ & 2010 & "Monte Carlo simulation is one of the earliest simulation methods." \\
\hline $\begin{array}{l}\text { Palisade } \\
\text { Corporation }\end{array}$ & 2010 & $\begin{array}{l}\text { "Monte Carlo Simulation is a proven technique used to simulate costs } \\
\text { and schedule. Monte Carlo Simulation makes use of probability } \\
\text { distributions in place of deterministic values to model the uncertainty } \\
\text { associated with a particular input and the possible outcomes that can } \\
\text { occur, thus allowing for better decision-making abilities when dealing } \\
\text { with such uncertainty." }\end{array}$ \\
\hline Chou & 2011 & $\begin{array}{l}\text { "A probabilistic technique that can be applied for cost estimation and } \\
\text { decision making." }\end{array}$ \\
\hline $\begin{array}{l}\text { Liu and } \\
\text { Zhang }\end{array}$ & 2012 & $\begin{array}{l}\text { "Monte Carlo is a method that substitutes point estimates with random } \\
\text { numbers obtained from probability density functions and then builds } \\
\text { models of possible results." }\end{array}$ \\
\hline
\end{tabular}

Therefore from the above definition, Monte Carlo Simulation can be concluded as a probability distribution in place of deterministic values to model the uncertainty. The clientcan make better decision making when dealing with a cost uncertainty in the construction project. The further subsection of the literature review will cover the relevant studies on the Monte Carlo simulation definition. Even there are varies in terms of Monte Carlo simulation, but most of them focus on the probability distributions, cost estimate and decision making.

\subsection{What Causes of Cost Overruns?}

The reason cost overrun stated by (Wilson, 2015) as follows;

a. Inaccurate or overly optimistic initial estimates;

b. Movements in "the economy.'

c. Poor Project Management;

d. Poor Cost Control;

e. Scope Creep;

f. Incomplete or inaccurate value engineering;

From the above reasons are valid in some cases, but the other reason due to the way of cost estimates are prepared by the Quantity Surveyor.

\subsection{Method of Estimating for Cost Prediction using Monte Carlo Simulation}

There are several methods used to estimate cost prediction; usually used cost contingency. At the simplest level, there is the "10\% rule", where the Estimate is increased by $10 \%$ (Wilson, 2015). He describes a slightly better method is the "expert judgement" method. The percentage relies on the experience and knowledge of the expert and remains subjective and in truth, provides a "gut feel" amount for the contingency. The better methods rely on estimating the risks involved for sub-sections of the project and then using some way to combine the risks for the individual sections to get the risk and required contingency for the overall project. This uses the same divide-and-conquer procedure that is used to generate 
the total cost, i.e. divide the project up into manageable sections and estimate the costs piece by piece and then combine them. Various heuristic methods that have been developed by different institutions, but the most widely accepted and fundamentally sound way of combining the individual risks is Monte Carlo simulation. Describe by Mun, (2015) Monte Carlo simulation in its simplest form is a random numbers generator that useful for forecasting, estimation, and risk analysis. A simulation calculates numerous scenarios of a model by repeatedly picking values from a user-predefined probability distribution for the uncertain variables and using those values for the model. As all those scenarios produce associated results in a model, each scenario can have a forecast. Forecasting is the act of predicting the future. It can be based on historical data or speculation about the future when no history exists. When historical data exist, a quantitative or statistical approach is best, but if no historical data exist, then potentially a qualitative or judgement approach is usually the only recourse (Mun, 2015).

\subsection{Types of Forecasting Method}

Forecasting method is divided into the following; Refer Figure 1.2 Forecasting Methods.

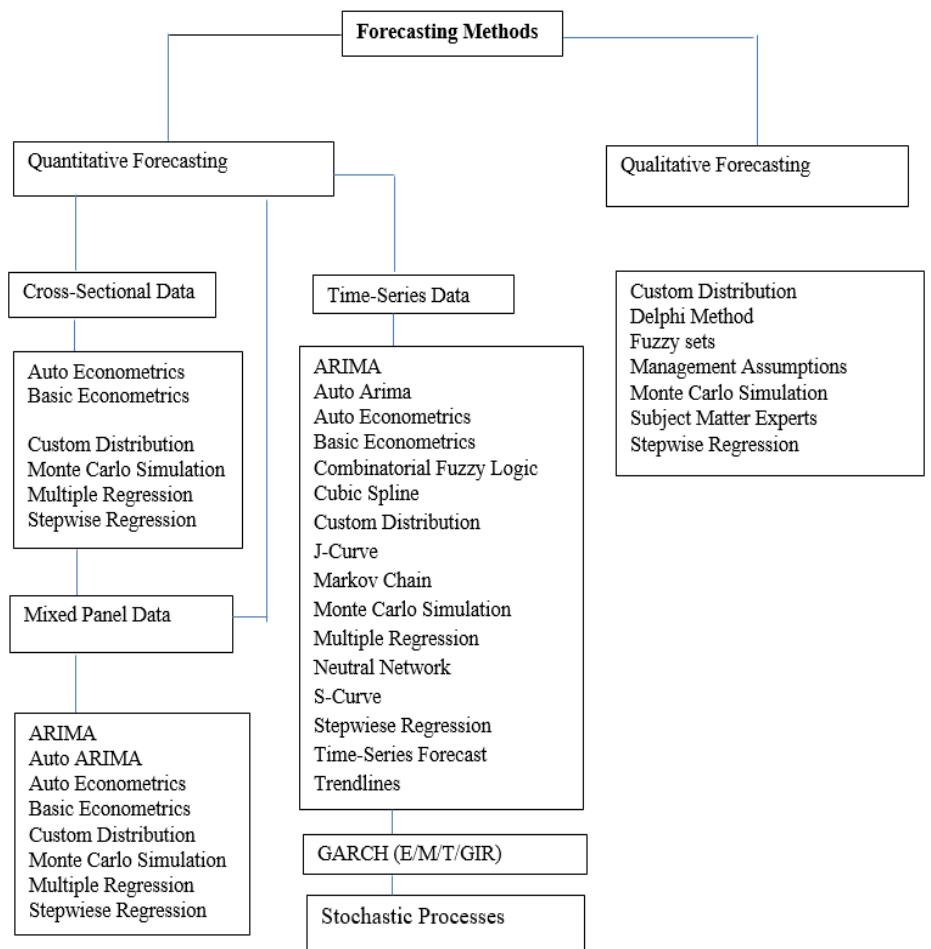

Figure 1.2 Forecasting Methods( Source: Mun, 2015) 
Generally, forecasting can be divided into quantitative and qualitative approaches. In this research, a qualitative approach was used to identify the forecasting cost in the green project. The component of value and green building element cover the development cost during the feasibility study stage (Shukur, 2016). However, In Malaysia, different green building rating tools exist such as the Green Performance Assessment System, PenarafanHijau, Green Real Estate, and GBI (Lim et al., 2016). GBI is Malaysia's first comprehensive rating system, developed by Malaysian Institute of Architects /PertubuhanArkitek Malaysia and the Association of Consulting Engineers Malaysia, to facilitate the accomplishment of sustainable development goals in Malaysia (GBI, 2018). $\mathrm{GBI}$ evaluates the environmental design and performance of green buildings in Malaysia based on six main criteria: sustainable site planning \& management, materials \& resources, water efficiency, indoor environment quality, innovation, and E.E. (GBI, 2018).

\subsection{Benefits of Monte Carlo Simulation for The Industry Players}

Ferry \& Brandon (1979) stated the benefits of Monte Carlo Simulation for the industry players are as follows;

a. To give confidence to the client concerning the expected cost of his projects,i.e. economic assurance;

b. To allow the quick development of a representing of building in such a way that its cost can be tested and analysed;

c. To establish a suitable system for advising the designer on the cost that is compatible with his own build-up of the design. It should be usable as soon as the designer makes the first decision that can be quantified, and should be capable of refinement, to deal with the more detailed decisions that follow after that;

d. To establish a link between the cost control of the design and how costs are generated and controlled on-site.

The Monte Carlo simulation method allows us Marseguerra and Zio, (2000) to consider various relevant aspects of systems operation that cannot be easily captured by analytical models (K-out-of-N, redundancies, stand-by nodes, etc.). With the advances of computer technology, the repetitiveness of the process and the handling of a massive amount of numerical information is no longer a barrier in implementing Monte Carlo simulation(Bennett and Ormerod, 1984). Monte Carlo became an alternative for the program evaluation and review technique for cost estimation (Balcombe and Smith, 1999; Khedr, 2006; Moselhi, 1997). Koo and Fischer (2000) reported that the simulation model could improve communication between project participants and safety by anticipating hazard in the construction site.

Specifically, Monte Carlo simulation helps project managers to quantify and justify project reserves based on the identified risk (Kwak and Ingall, 2007). Furthermore, this approach can be used to determine the final budget at project completion and contingencies estimation, which can be calculated based on the probability distribution of the final budget (Kwak and Ingall, 2007). 


\subsection{Process of Monte Carlo Simulation}

The general processes of simulation include data collection, random number generation, formulation of the model, data analysis, and visual presentation (Chou, 2011). This approach uses a large number of simulated trials and sampling technique to approximate a solution to a problem (Ashworth, 2004; Grinstead and Snell, 2012), such as developing realistic cost estimate (Khedr, 2006).

Lorance and Robert (1999) list the various steps of carrying out a "Monte Carlo simulation". The first step is to define the capital resources by developing the deterministic model of the Estimate. The second step is to identify the uncertainty in the Estimate by specifying the possible values of the variables in the Estimate with probability ranges (distributions). The third step is to analyse the Estimate with the simulation. The model is run (iterated) repeatedly to determine the range and probabilities of all possible outcomes of the model.

Through a series of simulation, Monte Carlo can estimate the total cost by producing the distribution of cost component. Monte Carlo calculates the total cost of a project by independent sampling from the distribution of cost component. In this process, the optimistic and pessimistic value can be both created. The random value generator can select values for the interval $(a, b)$ and then the frequency of data can be determined based on the distribution (Chen, 2013). The prediction shows based on Figure 1.3 below;

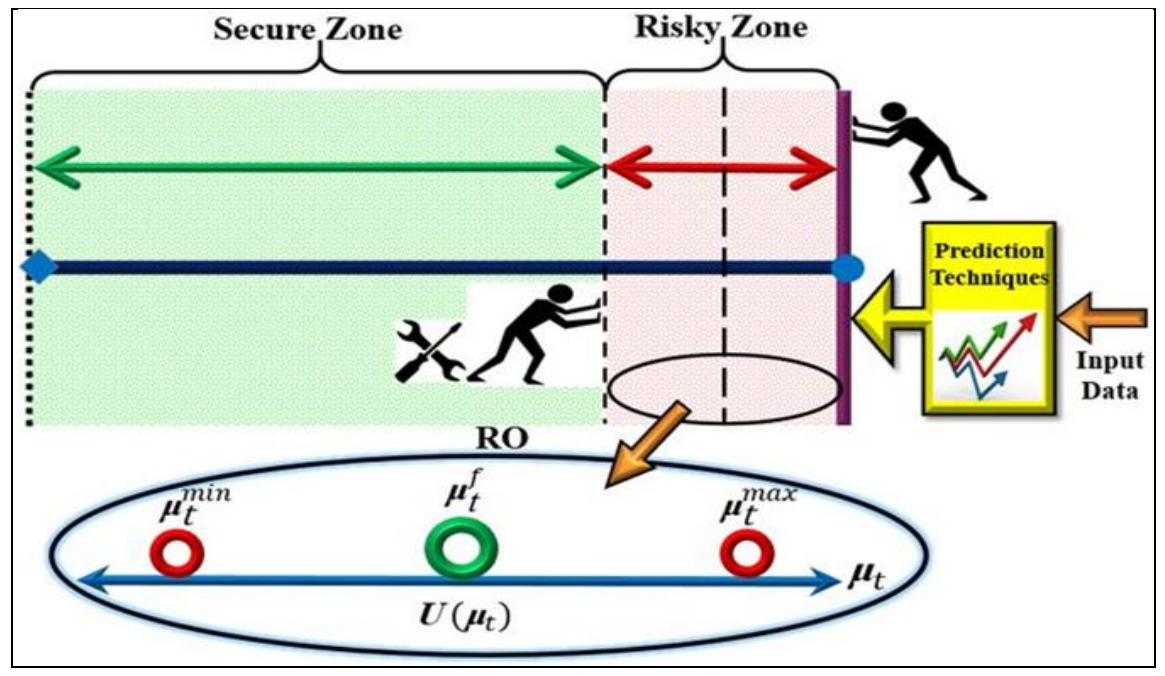

Figure 1.3 shows Prediction Techniques in Monte Carlo Simulation (Source: "Robust Design of Microgrids with Reconfigureable Topology under Several Uncertainty," 2017) 
This method can be applied while predicting the cost of development by the Quantity Surveyor in the green building project. The formula applies as follow;

\section{$D C=P D C+C C+P+x \% C+y \% G B$}

By using Monte Carlo, the Quantity Surveyor can convince the client either the justification of $\mathrm{x} \%$ for contingency and $\mathrm{Y} \%$ for Green Building is accurate for cost estimate proposes for the project. This simulation is crucial for the client to ensure the viability of the project is worth for investment. Therefore, it can reduce the cost of overrun in the project and benefit received in term of quality of life for the client in the project development.

\subsection{Methodology}

The research uses a qualitative method which consists of a case study approach and document analysis. Three (3) projects of the case study were selected. Cost prediction was analysed using Monte Carlo simulation software. The methodology used to estimate the building cost in the green building project. The building cost is a critical element in the new development and needs to be appropriately evaluated by the Quantity Surveyor. For forecast statistics, a distribution's location or central tendency (expected returns) is calculated; the second tales describe its width or spread (risk); the third moment, its directional skew (most probable events); and the fourth moment, its peakedness or thickness in the tails (catastrophic losses or gains). The limitation of this research only concentrated on the green building project. All four events need to evaluate and interpreted to provide a more comprehensive view of the project under analysis. Steps of the study using the procedure explained by (Barreras, 2011) as follows;

a. Compute initial Estimate (feasibility study stage)

b. Determine correlations

i. Between Estimate Line Items

ii. Between Risk Drivers

iii. Between line items and risks

c. Build a model

d. Run Monte Carlo Simulation

e. Analyse the result

\subsection{Compute initial Estimate (feasibility study stage)}

As the project defines the scope and prepares cost estimate for the various packages, it is crucial to capture the detail from the selected project. Cost estimate for prediction must 
include worst case, best case, and most likely values. This often referred to as a three-point estimate. Raw data is collected on cost and its relationship to design variables.

\subsection{Determine correlations}

Correlations can exist between any two or more items in the cost estimate, between risk events, and between risk event and cost estimate items. It is crucial to have a crossdiscipline review of all correlations to ensure that all functional team leads agree with the correlations proposed for the Monte Carlo Simulation.

\subsection{Build a Model}

The Monte Carlo Simulation models should be structured to be able to demonstrate both the value of the risk treatments or response plans and the amount needed for contingency reserve. It is essential to carefully review the project assumptions and constraint at this point to ensure appropriate consideration is given when constructing the model.

\subsection{Run Monte Carlo Simulation}

The Monte Carlo Simulation software will have several sets to predict the cost estimate at the required level. What probability does management want to use to determine contingency for the proposed project either $80 \%$ or $90 \%$ for final project setting or need to reserve for management cost?Optimising models are used to select the best alternatives cost estimate from the results of the previous models, based on criteria determined by the Quantity Surveyor.

\subsection{Analyse the result}

The results are the most crucial step of the entire process. The results must well be understood by the Quantity Surveyor and Client. The results need to communicate on the amount of contingency element, distribution between one item is very tight or narrow and the deterministic value percentage at the area of baseline or below. Analytical and predictive models are then used to explore cost situation and changes in the design variables.

\subsection{Results}

The findings show that by using Software, capturing the data needed to build and simulate project risks and cost Estimate via a monte Carlo simulation is considered accurate. The client is more confident to make a decision making to proceed with the proposed project as compare using a conventional approach of the Estimate to predict the cost in the construction project. 


\subsection{Discussion}

From this paper, Monte Carlo is a software used to predict the event of forecasting and Optimization software. The Software is written in Microsoft.NET C\# and function together with Excel as the add-in. Therefore, this Software is crucial to be used to predict the cost of estimation prepare by the Quantity Surveyor. From the literature review, the importance of this Software to be used to preclude cost overrun occurs in the construction project.The methodology used is a qualitative approach. The actual case study selected are Hospital projects which category as a Green Building Index. Through this modelling, it can convert all the disorganized data to a suitable form in a statistical method.

\subsection{Conclusion}

This paper urges the need for research to help the industry players or practitioner to understand the importance of this software application for the process of decision making to identify risk and the worth for money during the preparation of the cost estimate. The Monte Carlo proved to be a vital tool to the clients, project manager and the Quantity Surveyor to predict the cost estimate and the uncertainty during the project undertaking. Through this approach, quality of life received by the client in investing budget without waste of propose funding in the construction project. The result shows through Monte Carlo simulation, and this method can predict the worst return from the accuracy of the estimation and given absolute confidence for project development in the construction project. Therefore, quality of life received by the client thorough successful implementation of the project according to time, cost and quality.

\section{Acknowledgement}

We would like to express my sincere gratitude to the Research Management Centre, UniversitiTeknologi MARA, Shah Alam for funding of this research through Lestari Grant.

\section{References}

Ali Touran, R. L. (2006). Modelling Cost Escalation in Large Infrastructure Projects. Journal of Construction Engineering and Management, 853-860.

An, S. H., \& Kang, K. I. (2005). A study on predicting construction cost of apartment housing using experts' knowledge at the early stage of projects. Journal of Architectural Institute of Korea, 21(6), 81-88.

Attalla, M., \&Hegazy, T. (2003). Prediction cost deviation in reconstruction project: Artificial neural networks versus regression. Journal of Construction Engineering and Management, ASCE, 129(4), 405-411.

Balcombe, K.G. \& Smith, L.E. (1999), "Refining the use of Monte Carlo techniques for risk analysis in project planning", The Journal of Development Studies, 36(2), 113-135. 
Bennett, J. \& Ormerod, R.N. (1984), "Simulation applied to construction projects", Construction Management and Economics, 2(3), 225-263

Chen, G., 2013. Monte Carlo simulation of $\pi$ and the discussion of variance reduction techniques. J. Convergence Inform. Technol., 8, 850-859.

Choi, J., \& Ryu, H.-G (2015). Statistical analysis of construction productivity for highway pavement operation. KSCE Journal of Civil Engineering. 19(5), 1193-1202.

Faris, K. R., \& D. Patterson. (2007). Managing Risk in the Project Portfolio. Conference Paper, Newtown Square: Project Management Institute.

Ferry, D. J., \& Brandon, P. S. (1979). Cost Planning of Building

El-Sadek, A. (2010) Monte Carlo Approach to Developing a Water Quality Process- Factor. International Journal of Water Resources and Environmental Management, 1, 97-104.

Grinstead, C.M. \& Snell, J.L. (2012), Introduction to Probability, American Mathematical Society, Providence.

Hertz, D. B. (1964). Risk Analysis in Capital Investment.

Hongxiang, C., \& Wei, C. (2013). Uncertainty Analysis by Monte Carlo Simulation in a Life Cycle Assessment of Water-Saving Project in Green Buildings. Information Technology Journal, 12(13), 2593-2598.

Jahangirian, M., Eldabi, T., Naseer, A., Stergioulas, L.K. \& Young, T. (2010), "Simulation in manufacturing and business: a review", European Journal of Operational Research, 203(1), 1-13.

Khedr, M.K. (2006), "Project risk management using Monte Carlo simulation", 50th Annual Meeting, AACE International, Las Vegas, NV.

Kwak, Y.H. \&Ingall, L. (2007), "Exploring Monte Carlo simulation applications for project management", Risk Management, 9(1), 44-57.

Liu, N. \& Q. Zhang. (2012). Asymmetric stochastic volatility model estimation using improved markov chain Monte Carlo method. Journal Convergence Information Technology., 7, 179-186. 